\title{
Effect of Short Fiber Fillers on the Optical Properties of Composite Resins
}

\author{
Sufyan Garoushi, Pekka K.Vallittu \& Lippo Lassila \\ Turku Clinical Biomaterials Centre- TCBC, Institute of Dentistry \\ University of Turku, Turku, Finland \\ $\&$ \\ Department of Biomaterials Science, Institute of Dentistry \\ University of Turku, Turku, Finland \\ E-mail: sufgar@utu.fi
}

Received: December 21, 2011

Accepted: January 5, 2012 Published: Apri1, 2012

doi:10.5539/jmsr.v1n2p174

URL: http://dx.doi.org/10.5539/jmsr.v1n2p174

\begin{abstract}
Objectives: The aim was to evaluate the effect of different fractions of fiber fillers on the translucency and color change of short fiber composite with various thicknesses.

Methods: Fiber composite resin was prepared by mixing resin matrix with various weight fractions of short (3 $\mathrm{mm}$ in length) E-glass fiber fillers $(0,11.7,21.0,28.5,34.7 \mathrm{wt} \%)$ and then silane treated particulate silica fillers were gradually added by using high speed mixing machine. Particulate filler composite resin without fibers was used as control. Composite resins disks of $10 \mathrm{~mm}$ in diameter and with various thicknesses $(1.0,2.0,3.0,4.0$, and $5.0 \mathrm{~mm})$ of each group were prepared $(\mathrm{n}=3)$. Translucency parameter $(\mathrm{TP})$ and color change $(\Delta \mathrm{E})$ were calculated over a white and black background using spectrophotometer to determine the CIELAB values of each specimen. Data were statistically analyzed with analysis of variance (ANOVA).

Results: ANOVA revealed that fraction of fiber fillers had a significant effect $(\mathrm{P}<0.05)$ on the translucency and color change values of the short fiber composite resin. Translucency values at various thicknesses of short fiber composite was significantly lower than particulate filler composite with same total fillers weight fractions.
\end{abstract}

Significance: Inclusion of short glass fiber fillers reduced the translucency values of the composite resins. Thus, the masking ability of short fiber composite resin at various thicknesses was better than particulate filler composite. Color change was also altered with an increase of fractions of fiber fillers.

Keywords: Translucency, Fiber composite, Fibers, Glass, Color change

\section{Introduction}

One of the major goals in esthetic restorative dentistry is to produce restorations that match the optical properties of natural tooth (Joiner, 2004). Color, translucency, fluorescence and opalescence are optical properties that give natural tooth its vital-looking appearance (Powers, 2006). Among these esthetic attributes, color and translucency have the greatest impact on the vital appearance of natural tooth because they are the most readily observed (Yu \& Lee, 2008a). Translucency is the ability of a layer of colored substance to allow the appearance of an underlying background to show through (Johnston, et al., 1995). It is usually determined by translucency parameter (TP) or contrast ratio (CR) (Johnston, et al. 1995, Miyagawa, et al., 1981). TP refers to the color difference between a uniform thickness of material over a black and a white background and corresponds directly to common visual assessments of translucency (Miyagawa, et al., 1981). The degree of color change can be affected by a number of factors, including the structure of composite resin, the degree of polymerization and water sorption (Powers, et al., 1978). The main component of composite resins that significantly affects the color and translucency is the inorganic filler. Many studies have focused on the influence of the filler on color and translucency of dental composites in terms of filler type, particle size and content (Emami, et al., 2005; Yu \& Lee, 2008; Lim, et al., 2008). 
Recently, short fiber reinforced composite was introduced as a dental restorative composite resin (Garoushi, et al., 2007a, 2007b, 2008). The composite resin is intended to be used in high stress bearing areas especially in molars. The results of the mechanical tests revealed substantial improvements in the load bearing capacity, the flexural strength and fracture toughness of dental composite resin reinforced with short E-glass fiber fillers in comparison with conventional particulate filler restorative composite resin (Garoushi, et al., 2007a, 2007b, 2011). The short fiber composite resin has also revealed control of the polymerization shrinkage stress by fiber orientation and, thus, marginal microleakage was reduced compared with a conventional particulate filler restorative composite resins (Garoushi, et al., 2008).

Glass fibers are translucent and the relative refractive indices of the two components, i.e. the resin matrix and the glass fiber fillers can affect the color and translucency. A previous investigations showed a relationship between fiber orientation and translucency characteristics of composite resin (Le Bell, et al., 2003, Chirdon, et al., 2006). It also seems possible that differences in fractions of fiber fillers might have a great effect on the optical properties of composite resin. Moreover, when a incremental layering technique is used, it would be beneficial to have information on optical properties of composite resin in order to establish a successful color match.

It was hypothesized that the addition of glass fiber fillers might further alter the optical properties of a composite resin. Therefore, the purpose of this study was to evaluate the color and translucency characteristics of short fiber reinforced composite with different fractions of fiber fillers and various thicknesses of the composite by using reflection spectrophotometry, based on the CIE (Commission Internationale de I'Eclairage) L a b color system.

\section{Materials and Methods}

Dimethacrylate (BisGMA 67\% [bisphenol A-glycidyl dimethacrylate], TEGDMA 33\% [triethylenglycol dimethacrylate], CQ and DMAEMA 0.7\% [camphorquinone and dimethylaminoethylmethacrylate]) resin consisting E-glass fibers with BisGMA-PMMA [polymethylmethacrylate, $\mathrm{M}_{\mathrm{w}}$ 220.000] resin matrix (everStick, StickTech Ltd, Turku, Finland) were used. The combination of BisGMA and PMMA formed semi interpenetrating polymer network (semi-IPN) during polymerization. Radio-opacity particulate fillers of $\mathrm{BaAlSiO}_{2}\left(3 \pm 2 \mu \mathrm{m}\right.$ in size) (Specialty Glass, USA) were incorporated to the resin system. Before the $\mathrm{BaAlSiO}_{2}$ filler particles were incorporated into the resin matrix, they were silane treated using previously defined technique (Söderholm, et al., 2000).

Short fiber composite resins were prepared by mixing cut E-glass fibers ( $3 \mathrm{~mm}$ in length and $15 \mu \mathrm{m}$ in diameter) and $\mathrm{BaAlSiO}_{2}$-radio-opacity-fillers were mixed in different weight fractions to the resin matrix. Classification of test groups according to the fillers is given in Table 1. The mixing was carried by using high speed mixing machine for $5 \mathrm{~min}$ (SpeedMixer, DAC, Germany, $3500 \mathrm{rpm}$ ). Particulate fillers composite resin without fiber fillers was used as control group.

Composite resins disks of $10 \mathrm{~mm}$ in diameter and with various thicknesses $(1.0 \mathrm{~mm}, 2.0 \mathrm{~mm}, 3.0 \mathrm{~mm}, 4.0 \mathrm{~mm}$, and $5.0 \mathrm{~mm})$ of each test material were prepared $(\mathrm{n}=3)$ by manual condensing of each resin into molds Composite resin was pressed between celluloid strips and glass plates to flatten and smoothen the surfaces. The composite was photo-polymerized for $40 \mathrm{~s}$ from both sides using a light source with an irradiance of 800 $\mathrm{mW} / \mathrm{cm}^{2}$ (Optilux-500, Kerr, CT, USA). After curing, the celluloid strips and glass plates were removed and specimens stored dry at room temperature for $24 \mathrm{~h}$ before measurement.

Color was measured according to the CIELAB color scale relative to the standard illuminant D65 over a white tile (CIE $L^{*}=99.25, a^{*}=-0.09$ and $\left.b^{*}=0.05\right)$ and a black tile (CIE $L^{*}=0, a^{*}=0.01$ and $\left.b^{*}=0.03\right)$ on a reflection spectrophotometer (CM-700d, Konica-Minolta, Japan). The aperture size was $\varnothing 3 \mathrm{~mm}$, and the illuminating and viewing configuration was CIE diffuse $/ 10^{\circ}$ geometry with the specular component included (SCI) geometry (Commission Internationale de l'Eclairage 2004).

The translucency of the resin composites at various thicknesses was obtained by calculating the color difference between the specimen over the white background and the specimen over the black background:

$$
\mathrm{TP}=\left[\left(\mathrm{L}_{\mathrm{W}} *-\mathrm{L}_{\mathrm{B}} *\right)^{2}+\left(\mathrm{a}_{\mathrm{W}} *-\mathrm{a}_{\mathrm{B}} *\right)^{2}+\left(\mathrm{b}_{\mathrm{W}} *-\mathrm{b}_{\mathrm{B}} *\right)^{2}\right]^{1 / 2}
$$

where the subscript ' $\mathrm{W}$ ' refers to the color coordinates over the white background and the subscript ' $\mathrm{B}$ ' refers to those over the black background (Yu \& Lee, 2008, Bin, et al., 2008).

The color differences $(\Delta \mathrm{E})$ of the fiber composite with different fiber fillers fractions was calculated from the mean $\Delta \mathrm{L}, \Delta \mathrm{a}, \Delta \mathrm{b}$ values for each specimen using the following formula (Yu \& Lee, 2008)

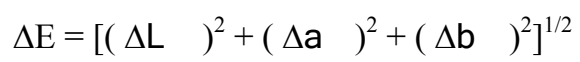


where, $\Delta \mathrm{L}, \Delta \mathrm{a}, \Delta \mathrm{b}$ are differences in $\mathrm{L}^{*} \mathrm{a}^{*} \mathrm{~b}^{*}$ values of $\mathrm{A} 2$ group (control) and other fiber composite groups.

To evaluate the differences in translucency and color variation values between the tested composite specimens at various thicknesses and fractions, data were statistically analyzed with analysis of variance (ANOVA) at the $\mathrm{P}<0.05$ significance level with SPSS (version 13, Statistical Package for Social Science, SPSS Inc, Chicago, IL, USA), followed by Tukey's post hoc analysis to determine the differences among the groups.

\section{Results}

The TP values of the tested composite resins (Groups A and B) with various fractions of fillers and fibers and thicknesses of the resin are presented in Figure 1. The background effect characterized by using TP values significantly correlated with filler fractions and thicknesses of the composite disks $(p<0.05)$ in both of the Groups, as filler fractions and thicknessese increased, the TP values decreased for each group. Mean TP values of the short fiber composite resin (Group B) showed statistically lower values $(p<0.05)$ than particulate filler composite resin (Group A) with similar weight fractions of fillers (wt \%).

By visual inspection of the composite discs, color differences were observed between the Groups A and B. Color change $(\Delta \mathrm{E})$ values of the composite resins with different fractions of fiber fillers and various thicknesses were in the range of 2.6-12.4 $\Delta \mathrm{E}$ units, whereas color change values of the composite resins with different fractions of particulate fillers only were in the range of 0.3-4.6 $\Delta \mathrm{E}$ units. As seen in Figure 2, color change $(\Delta \mathrm{E})$ of the composite with high fractions of fiber fillers displayed the highly statistically significant differences $(p<0.05)$ values compared to other composites with lower fractions of fiber fillers but similar thicknesses. Maximum difference in color was observed with $\Delta \mathrm{L}$ values, denoting the change in lightness of color, followed by difference in the blue-yellow axis, as indicated by the higher values of $\Delta b$.

\section{Discussion}

Color strongly influences restoration appearance, but geometric attributes such as translucency also influence appearance (Yu \& Lee, 2008). In 'through and through' class III and IV restorations or in the presence of discolored tooth structures, the harmonization of restoration color with the natural tooth system is made even more difficult by the transmission of background color (Bin, et al., 2008). The translucency parameter of a material refers to the difference in color between a uniform thickness of the material over a white background and the same thickness of the material over a black background and provides a value corresponding to the common visual perception of translucency (Yu \& Lee, 2008b; Kim, et al., 2009). A higher value for the translucency parameter represents greater translucency; if the material is completely opaque, the value of this parameter is zero (Yu \& Lee, 2008a; Yu \& Lee, 2008b; Kim, et al., 2009). Although there have been several studies on the translucency and color of composite resins, no one has examined the effect of short fiber fillers fractions on translucency characteristic and color change of composite resin at various thicknesses.

The general trend noted in particulate fillers composite resin (Group A, control) and short fiber fillers composite resin (Group B) was that translucency decreased with increased filler fractions and thicknesses (Figure 1). This is in accordance with $\mathrm{Yu}$ and Lee, which showed that mean TP values of flowable composite resin with different thicknesses were higher than those of the corresponding universal composite resin of the same brand, which reflects the fact that the less the filler content is, the higher is the translucency (Yu \& Lee, 2008a). There is an overall decrease in translucency of short fiber reinforced composite as compared with particulate filler composite resin (control) with same range of fillers fractions. This is clinically significant finding for masking e.g. a stained tooth. This effect may be attributed to the scattering effects by glass fiber fillers, thus allowing less light to be transmitted through the composite structure. Le Bell et al. and Lehtinen et $a l$. have shown that unidirectional E-glass fiber-reinforced composites conduct and scatter the light better than conventional composite resins (Le Bell, et al., 2003; Lehtinen, et al., 2008). They also showed that by polymerization, the monomer system to polymer, the light scattering improves. However, the short E-glass fibers are randomly oriented in the tested experimental fiber composite. Chindron et al. showed that orientation of the fiber fillers affects the absorption and scattering coefficient which is necessary to understand and predict the translucency of composites at various thicknesses (Chirdon, et al., 2006).

Discoloration can be evaluated by visual and instrumental techniques. Spectrophotometry, used in our investigation, can eliminate the subjective interpretation of visual color comparison and it has been reported to be a reliable technique in dental materials studies (Yannikakis, et al., 1998; Reis, et al., 2003). Overall color change $(\Delta \mathrm{E})$ is significant between the short fiber composite (Group B) and particulate filler composite (Group A). As seen in Figure 2, $\Delta \mathrm{E}$ value of the composite with high fiber fillers fractions displayed the highest statistically significant $(p<0.05)$ mean color difference compared to other composites with lower fiber fillers 
fractions at similar thicknesses. On other hand, color change was not significant with increasing particulate fillers fractions in composite resins (Group $\mathrm{A}$ ). These significant $\Delta \mathrm{E}$ values may arise from more than one factor. It may involve scattering effects, refraction and dispersion. The refractive index of glass fiber fillers is different from that of the surrounding composite matrix along with its particulate fillers (Sampath \& Ramachandra, 2008) This might explain the reduction in $\Delta \mathrm{L}$ values and hence the darker appearance of short fiber composite (Group B) as compared with the particulate fillers composite (Group A). In other words, this can be due to a lesser amount of light being reflected back and more being scattered away or absorbed.

In addition to these effects, translucency and color change values may also be affected by the presence of small unavoidable voids in mixing and preparing the experimental short fiber fillers composite resins.

It was reported that water has some influences on the optical properties of composite resins and our specimens were stored dry before color measurement, which is a limitation of this in vitro research.

\section{Conclusions}

Within the limitation of the present study, inclusion of short glass fiber fillers reduced the translucency values of the composite resins. Thus, the masking ability of short fiber composite at various thicknesses was better than particulate filler composite resins. Color change was also altered with an increase of fiber fillers fractions.

\section{References}

Chirdon, W. M., O'Brien, W. J., \& Robertson, R. E. (2006). Diffuse reflectance of short-fiber-reinforced composites aligned by an electric field. Dent Mater, 22, 57-62. http://dx.doi.org/10.1016/j.dental.2005.03.004

Commission Internationale de l'Eclairage, CIE. (2004). Colorimetery-technical report $\left(3^{\text {rd }}\right.$ ed). Vienna: Bureau Central de la CIE. CIE Publication No. 15.

Emami, N., Sjodahl, M., \& Soderholm, K. J. (2005). How filler properties, filler function, sample thickness and light source affect light attenuation in particulate filled resin composites. Dent Mater, 21, 721-730. http://dx.doi.org/10.1016/j.dental.2005.01.002

Garoushi, S, Vallittu, PK, Watts, DC, \& Lassila, LVJ. (2008). Polymerization shrinkage of experimental short glass fiber reinforced composite with semi-inter penetrating polymer network matrix. Dent Mater, 24, 211-215. http://dx.doi.org/10.1016/j.dental.2007.04.001

Garoushi, S., Vallittu, P. K., \& Lassila, L. V. J. (2007a). Short glass fiber reinforced restorative composite resin with semi-interpenetrating polymer network matrix. Dent Mater, 23, 1356-1362. http://dx.doi.org/10.1016/j.dental.2006.11.017

Garoushi, S., Vallittu, P. K., \& Lassila, L. V. J. (2007b). Direct restoration of severely damaged incisors using short fiber-reinforced composite resin. $J$ Dent, 35, 731-736. http://dx.doi.org/10.1016/j.jdent.2007.05.009

Garoushi, S., Vallittu, P., \& Lassila, L. V. J. (2011). Fracture toughness, compressive strength and load-bearing capacity of short glass fiber-reinforced composite resin. Chin J Dent Res, 14, 15-19.

Johnston, W. M., Ma, T., \& Kienle, B. H. (1995). Translucency parameter of colorants for maxillofacial prostheses. Int $J$ Prosthodont, 8, 79-86.

Joiner, A. (2004). Tooth color: a review of the literature. $J$ Dent, 32, 3-12. http://dx.doi.org/10.1016/j.jdent.2003.10.013

Kim, S. J, Son, H. H., Cho, B. H., Lee, I. B., \& Um, C. M. (2009). Translucency and masking ability of various opaque-shade composite resins. J Dent, 37, 102-107. http://dx.doi.org/10.1016/j.jdent.2008.10.002

Le Bell, A. M., Tanner, J., Lassila, L. V., Kangsniemi, I., \& Vallittu, P. K. (2003). Depth of light-initiated polymerization of glass fiber-reinforced composite in a simulated root canal. Int J Prosthodont, 4, 403-408.

Lehtinen, J., Laurila, T., Lassila, L. V. J., Tuusa, S., Kienanen, P., Vallittu, P. K., \& Hernberg, R. (2008). Optical characterization of bisphenol-A-glycidyldimethacrylate-triethylene glycoldimethacryalate monomers and copolymers. Dent Mater, 24, 1324-1328. http://dx.doi.org/10.1016/j.dental.2008.02.012

Lim, Y. K., Lee, Y. K., Lim, B. S., Rhee, S. H., \& Yang, H. C. (2008). Influence of filler distribution on the color parameters of experimental resin composites. Dent Mater, 2008, 67-73. http://dx.doi.org/10.1016/j.dental.2007.02.007

Miyagawa, Y., Powers, J. M., \& O'Brien, W. J. (1981). Optical properties of direct restorative materials. J Dent Res, 60, 890-894. http://dx.doi.org/10.1177/00220345810600050601

Powers, J. M. (2006). Restorative dental materials (12 ${ }^{\text {th }}$ ed). St. Louis: Mosby. 35-42. 
Powers, J. M., Dennison, J. B., \& Lepeak, P. J. (1978). Parameters that affect the color of direct restorative resins. J Dent Res, 57, 876-880. http://dx.doi.org/10.1177/00220345780570090701

Reis, A. F., Giannini, M., Lovadino, J. R., \& Ambrosano, G. M. (2003). Effect of various finishing systems on the surface roughness and staining susceptibility of packable composites resin. Dent Mater, 19, 12-18. http://dx.doi.org/10.1016/S0109-5641(02)00014-3

Sampath S., \& Ramachandra, G. (2008). Effect of glass fibers on light transmittance and color of fiber-reinforced composite. Dent Mater, 24, 34-38. http://dx.doi.org/10.1016/j.dental.2006.12.010

Söderholm, K. J., Yang, M. C., \& Garcea, I. (2000). Filler particle leachability of experimental dental composites. Eur J Oral Sci, 108, 555-560. http://dx.doi.org/10.1034/j.1600-0722.2000.00919.x

Yannikakis, S. A., Zissis, A. J., Polyzois, G. L., \& Caroni, C. (1998). Colour stability of provisional resin restorative materials. J Prosthet Dent, 80, 533-539. http://dx.doi.org/10.1016/S0022-3913(98)70028-9

Yu, B, \& Lee, Y. K. (2008). Differences in color, translucency and fluorescence between flowable and universal resin composites. J. Dent, 36, 840-846. http://dx.doi.org/10.1016/j.jdent.2008.06.003

Yu, B., \& Lee, Y. K. (2008a). Influence of color parameters of resin composites on their translucency. Dent Mater, 24, 1236-1242. http://dx.doi.org/10.1016/j.dental.2008.01.016

Yu, B., \& Lee, Y. K. Translucency of varied brand and shade of resin composites. Am J Dent 2008b, 21, 229-232.

Table 1. Classification of test groups used in the study according to their filler content and composition $(\mathrm{n}=3$, per group)

\begin{tabular}{|c|c|c|c|}
\hline Groups & Fibers (wt\%) & Particulate fillers (wt\%) & Resin matrix (wt\%) \\
\hline A1 & 0 & 33.3 & 66.7 \\
\hline A2 & 0 & 41.1 & 58.9 \\
\hline A3 & 0 & 47.3 & 52.7 \\
\hline A4 & 0 & 52.3 & 47.7 \\
\hline B1 & 11.7 & 29.4 & 58.9 \\
\hline B2 & 21.0 & 26.3 & 52.7 \\
\hline B3 & 28.5 & 23.8 & 47.7 \\
\hline B4 & 34.7 & 21.7 & 43.6 \\
\hline
\end{tabular}

0: No fiber fillers; A: experimental particulate fillers composite; B: experimental short fiber fillers composite 


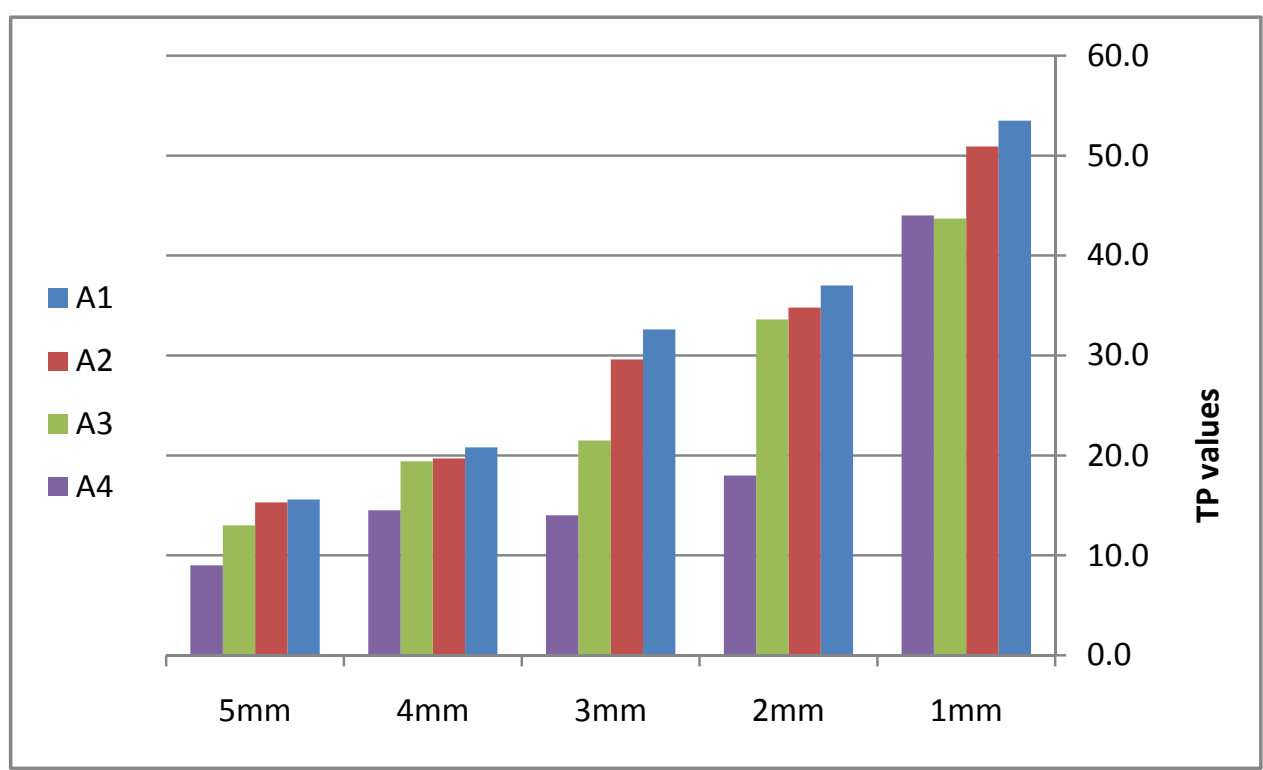

Figure 1a. Mean TP values of the particulate filler composites (Group A) with various fractions of fillers and thicknesses of the disc

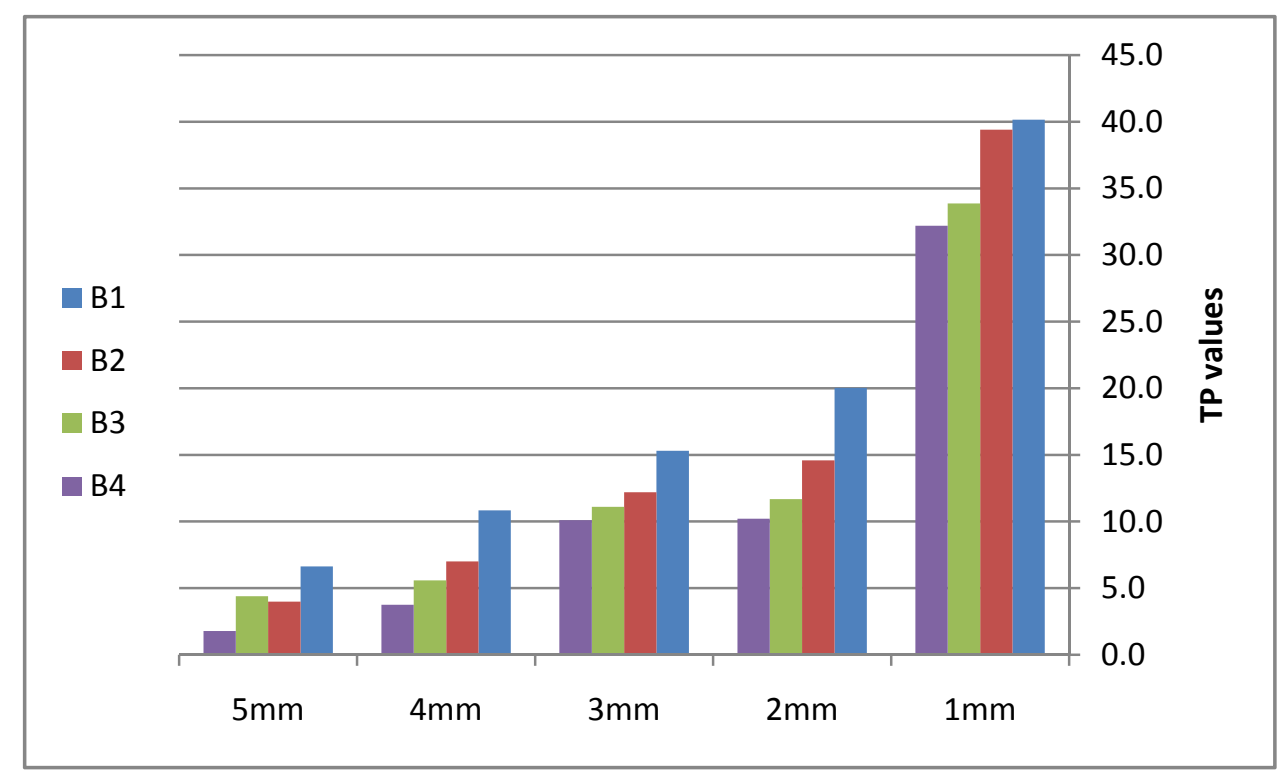

Figure 1b. Mean TP values of the fiber filler composites (Group B) with various fractions of fiber fillers and thicknesses of the disc 


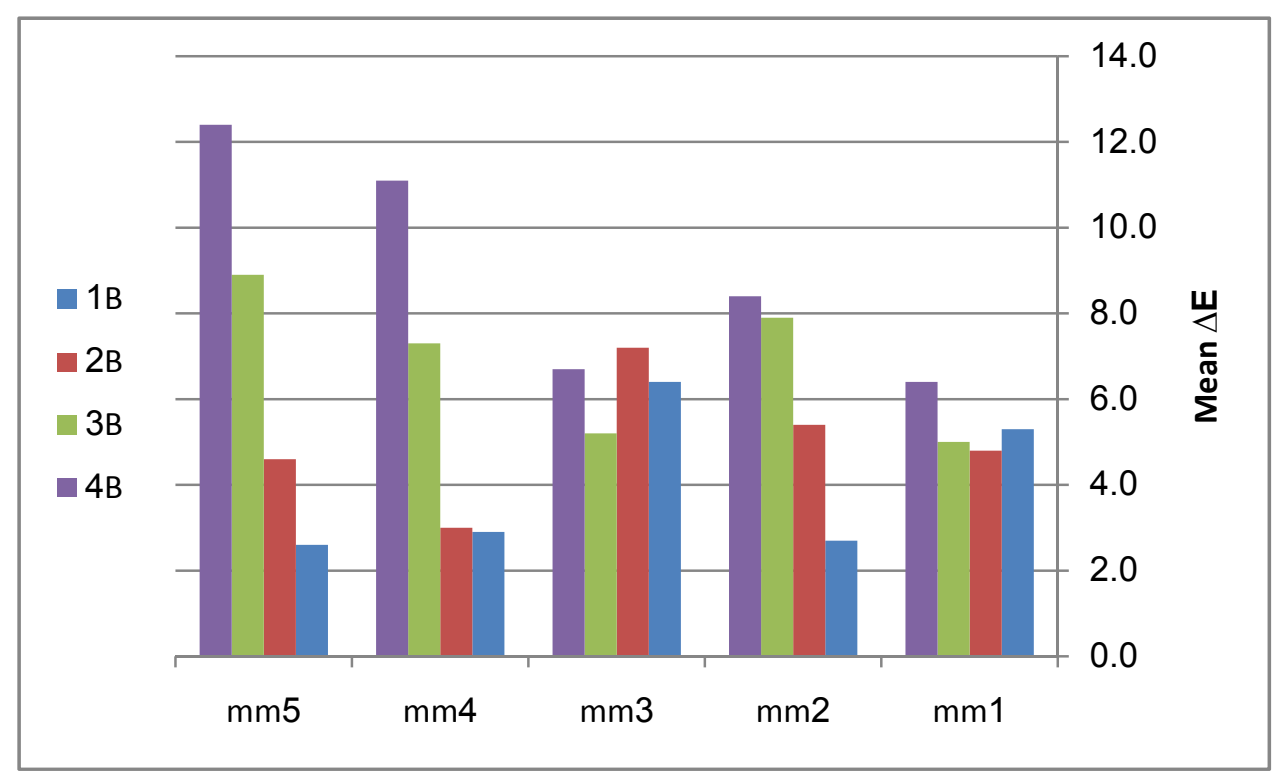

Figure 2. Mean values of color change $(\Delta \mathrm{E})$ of the fiber composites (Group B) with various fractions of fiber fillers and thicknesses of the disc 